D.O.I: $10.3895 /$ gi.v10i2.1674

\title{
ANÁLISE DA CAPACIDADE DE PROCESSO ATRAVÉS DE CONTROLE ESTATÍSTICO DA QUALIDADE DE MOLDURAS DE MADEIRA NO NORTE DO PARANÁ
}

\section{PROCESS CAPABILITY ANALYSIS THROUGH STATISTICAL QUALITY CONTROL OF A FRAME INDUSTRY IN NORTH PARANÁ}

\author{
Glaucia Aparecida Prates ${ }^{1}$; Reinaldo da Silveira Garcia ${ }^{2}$ \\ ${ }^{1}$ Universidade Estadual Paulista- UNESP \\ glaucia@itapeva.unesp.br \\ ${ }^{2}$ Universidade Estadual Paulista- UNESP \\ reinaldo.garcia.37@facebook.com
}

\begin{abstract}
Resumo
O presente estudo de Controle Estatístico de Processo - CEP, realizado em uma das etapas de produção de uma indústria de molduras, teve como objetivo avaliar a capacidade do processo. Considerando assim pontos do processo que necessita de melhorias já que não atendem bem as especificações. Avaliando as necessidades que a empresa necessita para a melhoria da gestão da qualidade, bem como as dificuldades que apresentam durante a implantação do CEP. O presente estudo teve como método a utilização do estudo de caso. Os resultados são apresentados através do estudo do nível de defeitos utilizando os diagramas de Pareto e gráfico de controle por ( $p$ ) fração defeituosa, e verificando a capacidade e estabilidade do processo utilizando histogramas. $O$ processo demonstrou a necessidade de melhorias no processo e na gestão da qualidade. Ao final do trabalho sugestões são apresentadas para melhorar o sistema de qualidade da empresa.
\end{abstract}

Palavras-chave: qualidade; controle estatístico de processo; indústria madeireira; molduras.

\section{Introdução}

Ao longo dos anos várias abordagens sobre qualidade foram criadas e modificado é um tema em constante evolução e é necessário para se ter um bom conhecimento para poder aplicá-lo nas organizações para que funcione e não se torne apenas algo sem lastro. Todos os envolvidos com o setor de qualidade devem entendê-la e saber diferenciar como utilizá-la em cada setor para assim ser bem aplicada.

Este trabalho aborda o estudo do Controle Estatístico de Processo - CEP, em uma das etapas de produção de uma indústria de molduras, tendo como objetivo utilizar a ferramenta de controle estatístico de processo (CEP) para avaliar a capacidade do processo.

Com o aumento da produção, e a inspeção $100 \%$ do tempo, tornando-se cara e ineficaz. Sendo assim a era da gestão corretiva, onde se identifica as causas e agindo sobre elas. Com isso o pilar 
dos erros que diz respeito à matéria-prima, equipamento e pessoal, nos quais podem apresentar causas, podendo afetar o desempenho do processo (BARÇANTE, 1998).

Segundo Rosário (2004) com a $2^{\text {a }}$ Grande Guerra Mundial, as organizações foram obrigadas a corrigir os erros da inspeção $100 \%$, através de técnicas de amostragem com isso o CEP - Controle Estatístico de Processo, que é uma ferramenta estatística para avaliar o processo, apresentou grande crescimento. A partir deste ponto começa a surgir o controle de qualidade através de métodos estatísticos. Focando as variáveis do processo e buscando sua correção.

\section{Objetivo}

Este trabalho tem como objetivo realizar o levantamento estatístico do processo de produção de molduras de uma indústria madeireira localizada no Norte do Paraná utilizando a ferramenta de controle estatístico de processo (CEP) para avaliar o processo, bem como os níveis de defeitos presentes, considerando as necessidades para a melhoria da gestão da qualidade e dificuldades que se apresentam durante a implantação do CEP.

\section{Revisão bibliográfica}

\subsection{CEP - Controle Estatístico de Processo}

O CEP - Controle Estatístico de Processo é uma ferramenta da Gestão da Qualidade que tem como idéia principal que melhores processos com menor variabilidade propiciam níveis melhores de qualidade na produção. Quando se fala de melhores processos e assim conseqüentemente melhores produtos isso implica diretamente em menores custos, pois quando se tem controle melhor do processo, menor e a variabilidade das não conformidades e menores são os rejeitos (CAMPOS; ROCHA, 2009).

O CEP é uma substituição da abordagem tradicional para controle da qualidade (por vezes referido como inspeção de controle de qualidade com base), que é bastante caro, ineficiente e pouco confiável e que fornece nenhum valor para a atividade de melhoria contínua (WICKRAMASINGHE e WIJEBAHU, 2012).

Para que um produto corresponda às exigências do consumidor deve ser produzido por um processo de produção estável e reprodutível, ou seja, este processo deve ser capaz de operar com a menor faixa de variabilidade possível em torno das dimensões nominais do produto (MONTGOMERY, 2004).

O gráfico de controle é uma ferramenta que disponibiliza graficamente os dados de um determinado item de controle coletados durante o processo, permitindo a visualização de seu estado de controle (WERKEMA, 2006). 
$\mathrm{Na}$ construção dos gráficos de controle deve-se especificar o tamanho da amostra e a frequiência de amostragem. Shewhart desenvolveu o conceito de subgrupos racionais que preconiza a retirada de pequenas amostras em intervalos regulares de tempo. Dentro deste conceito, as amostras ou subgrupos devem ser selecionados de tal modo que, se estiverem presentes causas especiais, a chance de diferenças entre os subgrupos será maximizada enquanto a chance de diferenças devidas a estas causas dentro de um subgrupo será minimizada (MONTGOMERY, 2004).

Existem gráficos de controle para atributos e para variáveis. Os gráficos para atributos avaliam o comportamento de características da qualidade que não podem ser representadas numericamente de modo adequado. Nestes casos o item inspecionado é avaliado e classificado como conforme ou não conforme. Quando a característica da qualidade pode ser mensurada em uma escala numérica como peso, temperatura, diâmetro, comprimento ou volume ela é denominada variável (MONTGOMERY, 2004).

O controle da média do processo ou do valor médio da característica da qualidade mensurada é normalmente feito através dos gráficos de controle para a média ou gráficos $x$. A variabilidade do processo pode ser monitorada tanto pelo gráfico de controle para o desvio padrão, denominado gráfico $S$ como para o gráfico de controle para a amplitude, o gráfico $R$.

Como é importante manter um controle tanto sobre a média do processo como sobre sua variabilidade, acompanha-se o processo através de um par de gráficos: $x$ e $R$ ou $x$ e $\mathrm{S}$ (MONTGOMERY, 2004).

Ambos os gráficos apresentam no eixo vertical os valores de medição do item de controle avaliado e no eixo horizontal, os pontos no tempo nos quais as medições são efetuadas. Existem três linhas horizontais que são a linha média, limite superior de controle e limite inferior de controle. A linha central ou linha média representa o valor médio da característica de qualidade quando o processo está sob controle (ALENCAR, 2004).

Quando o processo está sob controle, todos os pontos se encontram dentro dos limites superior e inferior de controle, entretanto, a maior parte dos processos não opera sob controle estatístico e o uso rotineiro destes gráficos é extremamente útil para auxiliar na identificação das causas de desvios. Buscando-se identificar estas causas, pode-se atuar sobre o processo, promovendo melhorias contínuas até que todos os pontos dos gráficos estejam situados dentro dos limites. Com isto diminui-se a variabilidade e aumenta-se o controle e a confiabilidade do processo (COSTA, 2005).

Além das informações sobre a estabilidade do processo, o CEP fornece subsídios para estimar a sua capacidade. Este índice está relacionado com a uniformidade do processo, pois correlacionam os limites de especificação com o desvio padrão populacional. A capacidade do 
processo é a medida de aceitabilidade da variação de um processo ao comparar sua variação natural com a faixa de especificação requerida (SLACK, 2009).

Sua análise é especialmente útil para predizer até que ponto o processo produzirá itens dentro dos limites de especificação, auxiliar no planejamento de modificações ou substituto de um processo, especificar indicadores de desempenho para um novo equipamento ou reduzir a variabilidade em um processo (MONTGOMERY, 2004).

Uma forma simples de expressar a capacidade é através da razão da capacidade do processo (RCP ou CP) expressada pela razão entre a diferença entre os limites superior (LSE) e inferior (LIE) de especificação e o desvio padrão. Quando a RCP é maior do que 1, significa que poucos itens não-conformes serão produzidos, porém, quando é menor do que 1 , indica que o processo é muito sensível e um grande número de unidades não-conformes pode ser produzido (MONTGOMERY, 2004).

Segundo Campos e Rocha (2009) o CEP permite que ações corretivas sejam realizadas antes que não conformidades ocorram, responde à pergunta se o processo está funcionando como deveria ou se está fora das especificações de qualidade. Executa ações apropriadas para obter e manter um estado de controle estatístico.

Todo produto pode apresentar falhas, defeitos resultando em um produto não conforme com o padrão, esta é a premissa do Controle de Processo, e essas falhas podendo ser causadas principalmente por falhas na matéria-prima, equipamento e pessoal, entre outros, mas estes três são os principais (CAMPOS e ROCHA, 2009).

Quando se fala em CEP a estatística é um fator importante, pois em uma fabrica realizar a inspeção a $100 \%$ ocasiona altos custos e resultados ineficientes, devido à dificuldade de manter o operador $100 \%$ do tempo em alerta. Por isso a amostragem do processo condiz melhor com os reais valores, com custos menores (CAMPOS e ROCHA, 2009).

Vários são os fatores que ocasionam a variação da qualidade, mas nem todos afetam a qualidade com a mesma intensidade. Para isso o CEP realiza um levantamento estatístico do processo com a ajuda de cartas de controle e gráficos, procurando nos gráficos por padrões que possam estar ocorrendo no processo, descobrindo quais são os erros significativos que geram grandes perdas e os erros menos significativos assim podendo atuar nos erros que realmente importam ao processo, melhorando assim o processo, proporcionando melhor controle do processo, garantindo a qualidade e gerando menores custos. O controle Estatístico de Processo age também no Controle de Qualidade, ou seja, através da inspeção por amostragem, atuando na prevenção de defeitos, pois busca a melhoria do processo, diminuindo os erros. Para utilizar o CEP diversas ferramentas da qualidade como citadas anteriormente são necessárias fazendo uma análise precisa e correta da amostragem realizada (KUME, 1993). 


\subsubsection{Vantagens e desvantagens do CEP}

Assim como todo método o CEP possui vantagens e desvantagens.

A lista abaixo mostra as principais vantagens da aplicação do CEP segundo Soares (2001 apud ROSÁRIO, 2004):

a) Melhoria da qualidade, melhor conhecimento do processo e onde introduzir melhorias;

b) Aumento da produção sob condições ótimas de produção;

c) Redução do custo por unidade;

d) Redução do nível de defeituosos;

e) Redução de refugo/retrabalho;

f) Economia no uso de materiais;

g) Redução dos gargalos de produção;

h) Avaliação científica das tolerâncias, ações baseadas em fatos e não em suposições;

i) Redução de inspeção em fim de linha de produção;

j) Baixo número de reclamações do consumidor.

As desvantagens da aplicação do CEP descritas por Rosário (2004) são evidenciadas logo abaixo:

a) Não indica condições de instabilidade do processo;

b) Não separa causas comuns de causas especiais, podendo gerar ações incorretas e custos decorrentes;

c) Se utilizado em processos não capazes pode piorar ainda mais o desempenho dos mesmos;

d) Dificuldade maior quanto à sua interpretação, uma vez que os pontos fora de controle não revelam especificamente qual ou quais variáveis, ou a combinação delas, causam o problema.

As desvantagens de implantação do CEP estão associadas às causas dos insucessos de uma implantação mal sucedida, ou seja, desde que ele seja bem implantado, o resultado apresenta lucros e os efeitos colaterais maléficos não são significativos (ROSARIO, 2004).

Segundo Montgomery (2004), as principais causas dos insucessos da implantação de CEP estão, em sua maioria, ligadas à execução de forma deficiente ou até mesmo incompleta de algumas das etapas necessárias para a implantação. Algumas destas causas estão listadas a seguir e devem ser objetivo de avaliação em auditoria de sistema e treinamento:

a) Falta de envolvimento da alta administração;

b) Não envolvimento de todas as áreas ou resistência a mudanças; 
c) Falta, perda ou não priorização ao programa;

d) Priorização errada das características de processo ou produto a serem controladas;

e) Falta de conhecimento necessário para aplicação de conceitos básicos de estatística;

f) Falta ou não acompanhamento de um cronograma de atividades;

g) Falta de ação corretiva por não investigação ou desconhecimento de causas comuns e especiais;

h) Falta de padronização das tarefas operacionais;

i) Falta ou falhas na divulgação do programa CEP na empresa ou espera de grandes resultados em curto prazo.

\subsubsection{Casos de implantação do CEP - dificuldade, melhorias e ajustes}

Abaixo são relatadas as dificuldades, melhorias e ajustes do CEP estudados por outros autores.

\section{Caso 1 - empresa de autopeças}

Segundo Torminato (2004) a Auto Peças S.A. é um exemplo de aplicação do CEP e Cartas de Controle com sucesso, mas segundo o autor este processo levou quase uma década para atingir os resultados esperados, sendo que a alta administração teve grande perseverança, pois considerou que é necessário insistir no treinamento em todos os níveis da empresa.

As cartas de controle nesta empresa surgiram a partir de problemas a serem resolvidos na produção e depois da implantação passaram a ser utilizadas em outros setores da empresa (TORMINATO, 2004). Segundo o autor as cartas de controle são comprovadamente uma ferramenta com eficácia para entender e fundamentar as ações tomadas.

As causas mais comuns de variabilidades na qualidade acontecem em função das diferenças ou inconsistências entre operários, lotes de matéria-prima, equipamentos e instrumentos de medição, desse modo, o controle destas causas pode ser feito através de treinamentos da equipe, mudanças na concepção do processo, controle sistemático da matéria-prima, manutenção preventiva, padronização das operações, etc (TORMINATO, 2004).

\section{Caso 2 - pequena empresa}

Segundo Indezeichak e Leite (2006) que realizou a implantação do CEP em uma pequena empresa uma das principais constatações da implantação do CEP deve ser considerada um processo de mudança organizacional e comportamental, sendo que seu sucesso depende do apoio total da gerencia, treinamento, desenvolvimento do quadro de funcionários, comprometimento das pessoas envolvidas nos processos, e principalmente, tomada de ações corretivas na ocorrência de causas especiais. 
Ainda segundo o autor, uma das dificuldades na implantação do CEP é ter acesso a toda a documentação necessária para poder iniciar o CEP, empresas que possuem em seu quadro, funcionários antigos que estão habituados com o sistema e impõe uma barreira na implantação do CEP. Empresas que já tiveram algum insucesso com alguma ferramenta de gestão de qualidade tendem a ter funcionários que se oponham as inovações propostas pela diretoria (INDEZEICHAK e LEITE, 2006). Para ocorrer sucesso na implantação, os treinamentos devem ser bem planejados e com metodologia bem definida (INDEZEICHAK e LEITE, 2006).

\subsection{Capacidade do processo}

O estudo da Capacidade de um processo refere-se à capacidade que este tem em produzir produtos que atendam as especificações de projeto e conseqüentemente, possam satisfazer as necessidades dos clientes quanto ao nível de qualidade esperada (ROSARIO, 2004).

Essa capacidade depende da variabilidade do processo, portanto, esta não está vinculada apenas a presença ou ausência de causas especiais (uma vez que o processo, mesmo na ausência de causas especiais, já possui uma variabilidade natural), embora seja evidente que desajustes e/ou falta de estabilidade do processo (provocados por causas especiais) reduzem sua capacidade e aumentam o número de itens não conformes produzidos (COSTA, 2004).

Para Rosário (2004), a capacidade de um processo envolve a comparação dos "Limites Naturais" do processo com os "Limites Especificados", sendo através desta comparação, classificado o processo quanto a sua capacidade em:

a) Processo Capaz: quando o resultado das medições encontra-se dentro dos limites de especificações de projeto, ou seja, estatisticamente não estão sendo produzidos produtos defeituosos;

b) Processo Não-Capaz: quando o resultado das medições revela itens fora dos limites das especificações de projeto, ou seja, estatisticamente existem indicações que estão sendo produzidos produtos defeituosos.

\subsection{1. Índices de capacidade de processo}

Existem alguns índices ou coeficientes usados em relação à capacidade do processo. $\mathrm{O}$ Cpk é o coeficiente de capacidade efetiva do processo. O Cp é o coeficiente de capacidade potencial do processo. O Cpk e $\mathrm{Cp}$ são muito utilizados em processos técnicos e raramente em processos administrativos, de serviços ou transações (ROSARIO, 2004).

Ainda segundo o autor, capacidade potencial do processo $\mathrm{Cp}$ é definida pela razão entre a dispersão permitida e a dispersão real. A dispersão permitida ou de especificação é a diferença entre o limite de Controle Superior (LCS) e o Limite de Controle Inferior (LCI). 
A verificação da capacidade de processo em atender com segurança as especificações foi demonstrada pelo cálculo do parâmetro Cpk definido pelas equações segundo Rosário (2004):

Figura 1 - Índice de capacidade do processo

\begin{tabular}{|c|c|}
\hline \multicolumn{2}{|c|}{ ÍNDICE DE CAPACIDADE DO PROCESSO } \\
\hline $\begin{array}{c}\text { Processo com Média X, } \\
\text { Desvio Padrão } \sigma \text { e Especificação }\end{array}$ & Indice de Capacidade do Processo \\
\hline Superior (USL) & $C_{p}=\frac{U S L-L C L}{6 \sigma}$ \\
$C_{\text {p }}=$ Minimo de \\
Inferior (LSL) & $\frac{U S L-\bar{X}}{3 \sigma} \mathrm{e} \frac{\bar{X}-L S L}{3 \sigma}$ \\
\hline Superior (USL) & $C_{p}=\frac{U S L-\bar{X}}{3 \sigma}$ \\
\hline Inferior (LSL) & $C_{p}=\frac{\bar{X}-L S L}{3 \sigma}$ \\
\hline
\end{tabular}

Segundo Costa (2004), quanto maior for o valor do CP, melhor o processo estará atendendo as especificações. O processo pode ser classificado em três tipos:

a) Cp menor que 1: processo incapaz, conforme Figura 2;

b) Cp igual a 1 e menor ou igual 1,33: processo razoavelmente capaz, conforme Figura 3;

c) Cp maior que 1,33: Processo capaz, conforme Figura 4.

O índice Cpk avalia a distância da média do processo aos limites da especificação, tomando aquela que for menor, e, portanto, mais crítica em termos de chances de serem produzidos itens fora de especificação (MONTIGOMERY, 2004).

Figura 2 - Exemplo de histograma com cp menor que 1

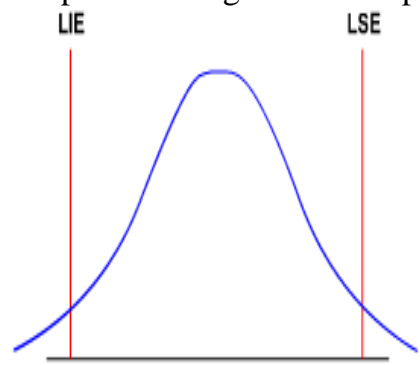

Fonte:Costa (2004)

Figura 3 - Exemplo de histograma com cp igual ou maior a 1 e menor ou igual 1,33

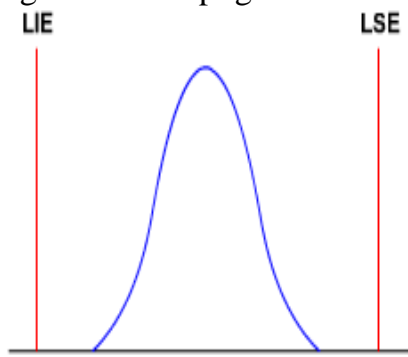

Fonte:Costa (2004) 
Figura 4 - exemplo de histograma com cp maior que 1,33

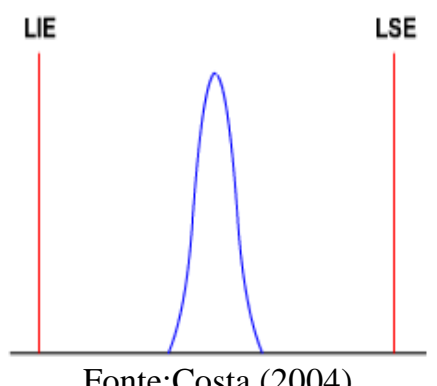

Fonte:Costa (2004)

\subsubsection{Variabilidade}

Quando do surgimento de problemas, a ação deve ser no processo (causa) que gerou o defeito e não no produto (efeito) em si (TORMINATO, 2004).

\subsubsection{Causas comuns}

Causa comum é definida como uma fonte de variação que afeta todos os valores individuais do processo. É resultante de diversas origens, sem que nenhuma tenha predominância sobre a outra. Um processo é dito sob controle, ou estatisticamente estável, quando somente causas comuns estiverem presentes e controladas (TORMINATO, 2004).

\subsubsection{Causas especiais}

As causas especiais, esporádicas, aleatórias ou, ainda, assinaláveis são fatores geradores de variações que afetam o comportamento do processo de maneira imprevisível, e não podem ser adequadamente explicadas, onde não se é possível obter um padrão.

A causa esporádica diferencia-se da causa comum pelo fato de produzir resultados totalmente discrepantes em relação aos demais valores.

Estas variações aleatórias são produzidas pelas interações entre mão-de-obra, máquinas, materiais e métodos. Exemplos de causas especiais são: desregulagem ocasional da máquina, um lote de matéria-prima com problema, quebra de uma ferramenta e outras (TORMINATO, 2004).

\subsection{Defeito e classificação de defeitos}

Todo processo pode apresentar em seus produtos defeitos, sendo alguns defeitos críticos e outros não, para isso é necessário conhecer os defeitos do processo e classificá-los de acordo com o nível de criticidade do produto (PALADINI, 2000):

Defeito nada mais é que uma não conformidade do produto quando comparado as suas especificações. Por sua vez, um produto é classificado como defeituoso em relação a um ou mais característicos da qualidade, se forem identificados um ou mais defeitos a ele associados (PALADINI, 2000). 
Em geral, podem-se classificar os defeitos de acordo com sua importância. Para tanto, utilizamse três categorias segundo Paladini (2004) logo abaixo:

a) Os defeitos críticos (ou graves) são defeitos associados à função essencial do produto, que impedem sua utilização efetiva e inviabilizam seu emprego para aquilo a que se propõe o produto;

b) Existem dois tipos de defeitos críticos os que impedem o uso do produto, afetando sua função essencial e os que não impedem o uso do produto, mas afetam as condições de contorno relativas ao uso do produto;

c) Os defeitos maiores são os que não impedem a utilização efetiva do produto em um dado momento, mas tende a curto ou em médio prazo, inviabilizar esta utilização, ou seja, são defeitos que comprometem a vida útil do produto. São classificados nesta categoria, ainda, defeitos que atingem a eficiência do produto, reduzindo sua capacidade de operação ou provocando custos mais altos que os normais devido aos problemas que acarretam ao seu funcionamento normal;

d) Por fim, os defeitos menores (ou irregularidades) são defeitos que não chegam a provocar alterações substanciais na função essencial do produto, mas podem ser atribuídos a imperfeições de acabamento.

\section{Metodologia}

Durante anos a empresa utiliza o CEP apenas como uma ferramenta simples, onde são apenas apresentados dados e nenhum dos defeitos é corrigido, então o intuito foi solucionar os defeitos da implantação antiga do CEP no processo de fabricação de molduras, melhorando a tomada de ação em tempo real para evitar problemas durante o processo.

\subsubsection{Implantação do processo}

A empresa já havia implantado o CEP, entretanto como a empresa voltou há atuar este ano, pois estava sem atividades, o CEP passou a ser reformulado, principalmente quanto as fichas de inspeção para atender as necessidades reais do processo, com isso novas fichas foram reformuladas neste ano principalmente a ficha de inspeção de Molduras a qual avalia os defeitos presentes na molduras, bem como as dimensões do produto.

\subsubsection{Método}

A princípio iniciou-se construção das cartas de controle por variáveis e atributos, bem como para construção do diagrama de Pareto, estratificação e histograma e utilizou-se para a geração dos gráficos o programa Excel e Minitab. 
A idéia desta nova implantação dos CEP foi devido a necessidade de obter no momento real, ou seja, realizada a inspeção, no mesmo momento gerar os gráfico para realizar uma avaliação e caso necessário interferir no processo antes que um erro maior ocorra.

\subsubsection{Monitoração}

Para a realização deste trabalho, foi monitorado durante 31 dias do mês de agosto de 2012, em dois turnos, o processo de fabricação de molduras, onde avaliou-se os níveis de defeitos existentes nas molduras.

\subsection{Estudo de caso}

Empresa Moldureira estabelecida no Norte do Paraná emprega mais de 400 colaboradores e têm como produto as molduras, batentes para portas e janelas, portas, kit porta pronta e guarnições. Tendo como mercado os Estados Unidos da América, Europa e Brasil. È transformadora de madeira de Pinus com certificação ambiental. Produzem batentes para portas e janelas, molduras, Portas, Kits Porta Pronta e guarnições. Fornece sua produção para o mercado interno e consumidores internacionais destes produtos.

\subsection{Processo de fabricação}

O escopo da pesquisa restringi-se ao processo de produção de molduras em 2 dois modelos: O processo de produção de molduras passa por vários setores, necessitando de um acompanhamento da produção para a minimização de perdas durante o processo produtivo.

\subsubsection{Fluxograma produção de molduras}

A seguir apresenta-se resumidamente o processo de produção de molduras. A Figura 4 descreve o processo em estudo. 
Figura 4 - Fluxograma produção (molduras)

FLUXOGRAMA DO PROCESSO DE PRODUÇÃO DE MOLDURAS

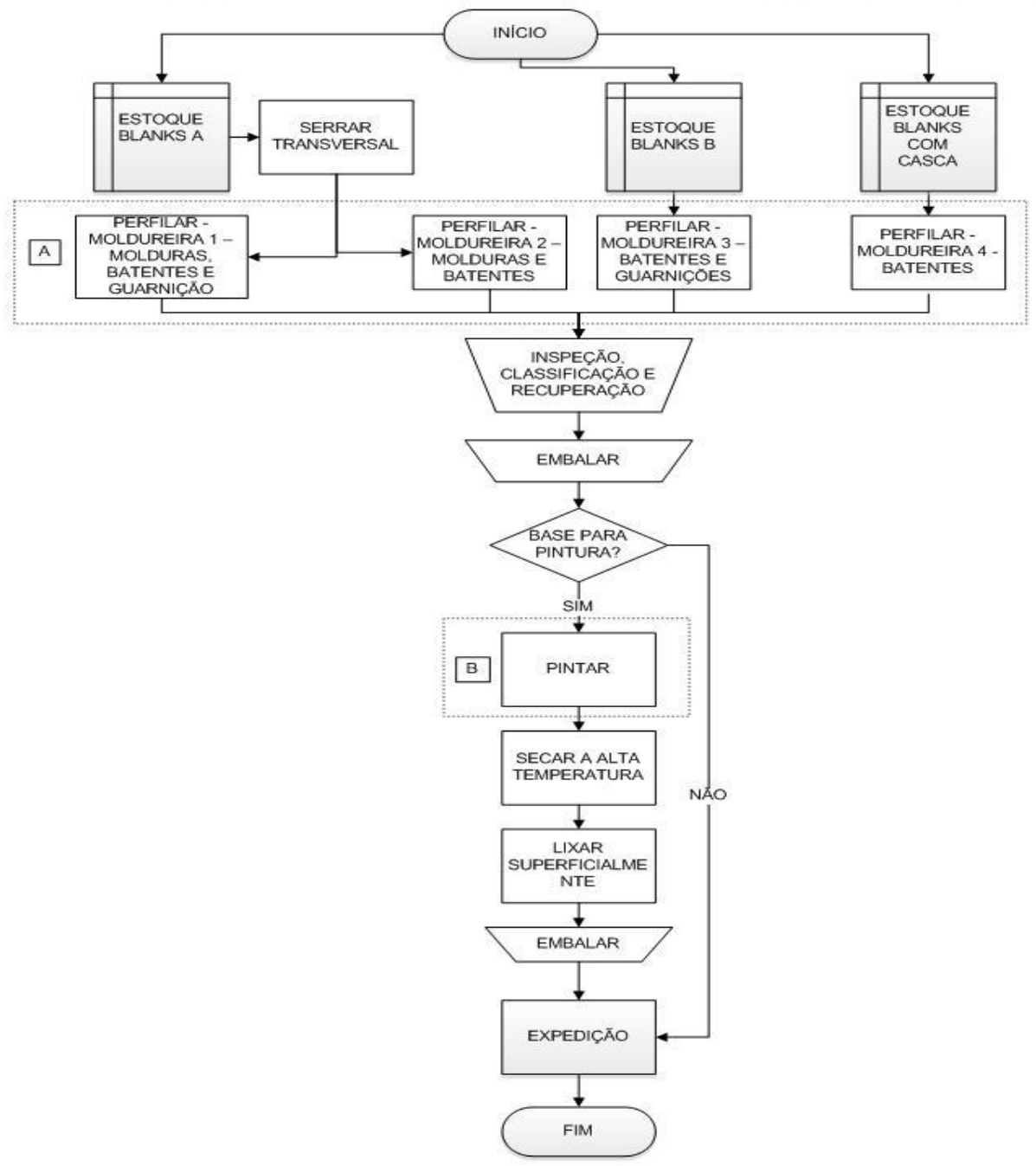

MEDIDAS DE CONTROLE

A - COMPRIMENTO, LARGURA, ESPESSURA, PERFIL E QUALIDADE VISUAL DAS MOLDURAS

a) Serra fita Transversal: Esta serra recebe os blanks e os corta longitudinalmente na espessura desejada da moldura e depois são passadas na moldureira;

b) Moldureira: máquina que com o auxilio de cabeçotes composto de faca, recebem o blanks e processam este, dando o perfil desejado, ao final do processo obtém a moldura nas dimensões requisitadas e inspecionadas numa mesa por funcionárias, e podendo seguir adiante, serem recuperadas ou descartadas. As peças recuperadas são peças com pequenas trincas, lascados, pontas de agulhas, mordidas e pequenos orifícios que podem ser tampados com massa e as peças que não tem como recuperar que são enviadas para o destopo em outros tamanhos para aproveitamento as demais; 
c) Pintura: caso a moldura seja crua esta passa por este setor e vai direto para o empacotamento e expedição, caso seja uma moldura que tenha que ter uma base branca esta passa por este setor e pintada e depois secada a altas temperaturas;

d) Lixamento: após a secagem as molduras com base branca recebem um lixamento superficial com lixas bem finas para acabamento, gradeadas e enviadas para a expedição;

e) Expedição: Setor onde os pacotes são preparados para o transporte e despachados.

\subsection{Defeitos do produto}

Um produto pode apresentar em sua linha de produção defeitos ou falhas, alguns defeitos são frequientes, outros esporádicos, as molduras apresentam alguns tipos de defeitos que devem ser avaliados. Para isso é realizada a inspeção por amostragem para fazer o levantamento dos problemas e suas respectivas soluções.

As molduras são avaliadas em duas partes, uma pela inspeção dimensional para classificar a moldura que estão dentro dos limites de espessura, largura, comprimento e perfil e a segunda que refere-se à inspeção de qualidade visual que serve para avaliar os defeitos presentes na moldura, verificando se os níveis de defeitos estão sendo controlados.

Após alguns estudos foi criada a ficha de Inspeção das Molduras e são avaliados todos os defeitos citados abaixo:

- Trincas - São fissuras que aparecem geralmente no perfil da moldura, conforme Figura 6.

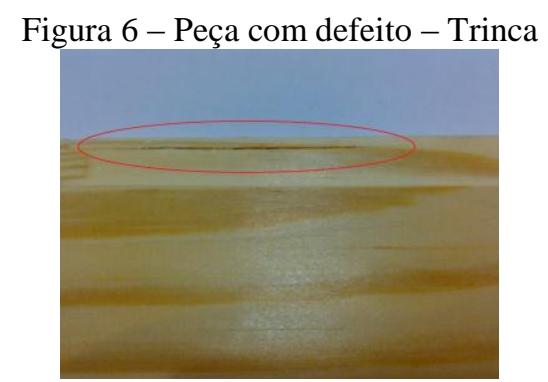

- Open Joint - ocorre quando as uniões do finger joint não estão ligadas completamente, quando há um espaço separando-as,conforme Figura 7.

Figura 7 - Peça com defeito - Open Joint 
- Lascado - são pedaços da madeira que podem lascar, geralmente nas laterais da peça, conforme Figura 8.

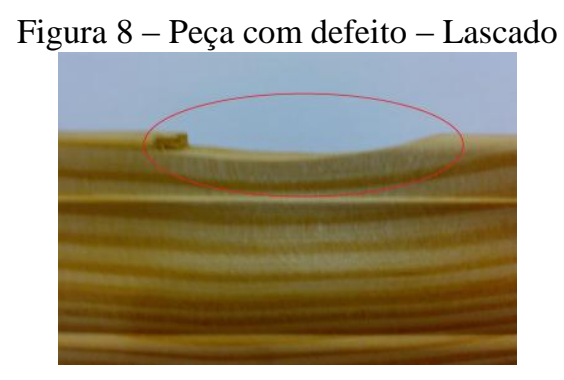

- Bolsa de resina - As bolsas e canais de resina são formações anelares, de comprimento e forma variados, caracterizando-se como uma formação anormal na madeira, provocando uma descontinuidade do lenho, conforme Figura 9.

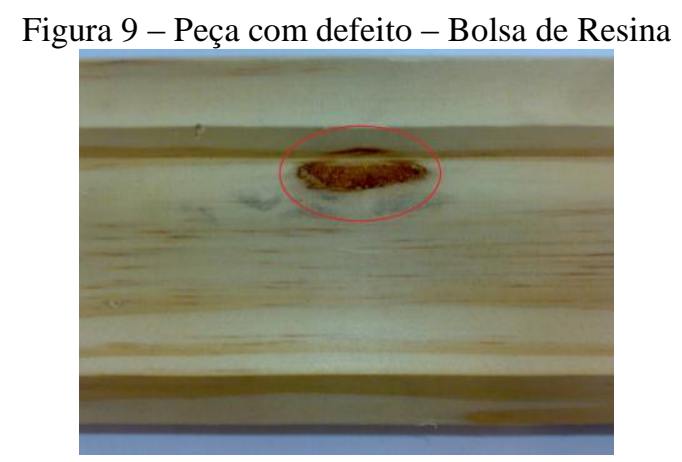

- Medula - A medula é o vestígio deixado no centro do tronco pela estrutura apical a partir da qual se desenvolveu o tronco da planta. É em geral uma fina estrutura (de alguns milímetros de diâmetro) conforme Figura 10.

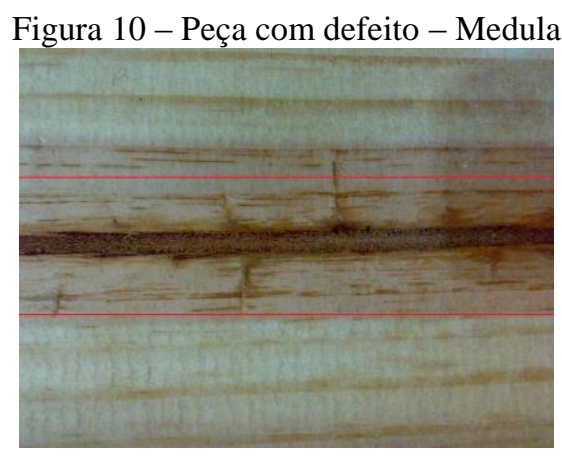

- Marca de rolo - São marcas rebaixadas causadas no perfil da moldura pelos rolos tracionadores da plaina moldureira, conforme Figura 11. 
Figura 11 - Peça com defeito - marca de rolo

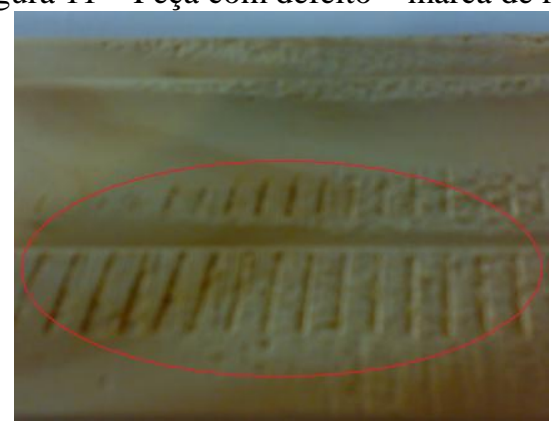

- Mordida - São marcas elevadas causadas no perfil da madeira, conforme Figura 12.

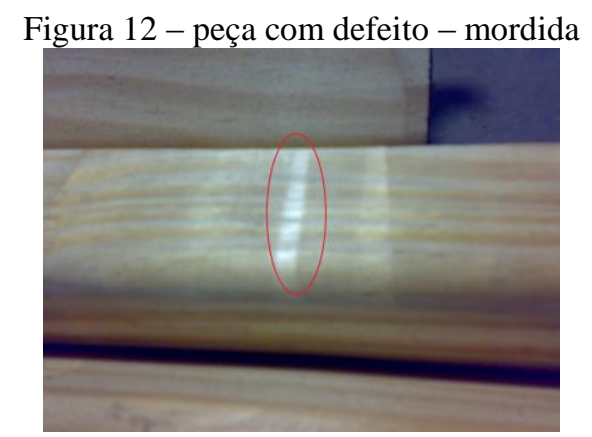

- Ponta de agulha - nas ligações de topo (Finger-Joint) bem na linha de junção aparecem pequenas falhas, conforme Figura 13.

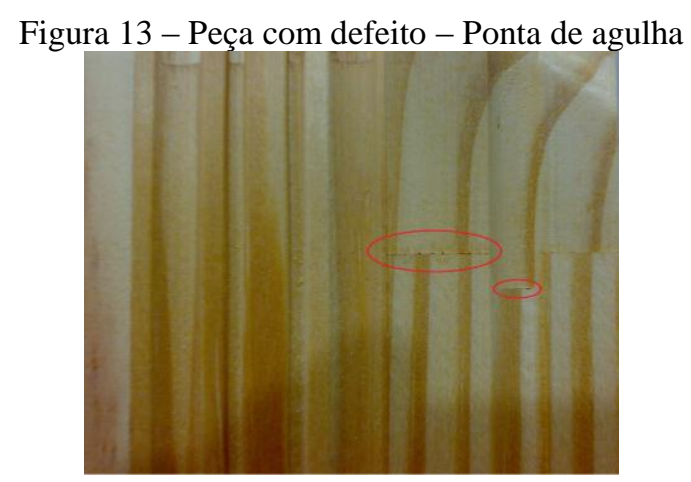

\subsection{Coleta de dados}

A inspeção das peças foi realizada por inspetores do Controle de Qualidade da Fábrica, os quais são responsáveis pela coleta de dados referentes às dimensões, perfil e qualidade visual das molduras, utilizando o sistema de amostragem de peças aleatórias, conforme as normas. Para isso o inspetor de qualidade seguia alguns passos para realizar essa coleta de dados:

a) Coleta de dados da moldura produzida no momento, dimensões de comprimento, espessura e largura que são retiradas no livro de desenho das molduras, Coleta de dados de cliente e PO (Pedido de Operação) que são retirados da folha de Planejamento de Produção que são entregues aos operadores das moldureiras; 
b) Utiliza-se o gabarito, para depois verificar se as amostras estão dentro do perfil (desenho da moldura);

c) Retirada de 10 molduras (amostras) durante o processo, de forma aleatória;

d) Inspeção dimensional da peça que visa verificar se a moldura está dentro dos limites de tolerância, na espessura, largura e comprimento.Sendo o Limite de tolerância para molduras +/$0,79 \mathrm{~mm}$;

e) Realiza-se a inspeção do perfil da peça para verificar se o desenho está correto e dentro dos limites de tolerância das dimensões;

f) Realiza-se a inspeção de qualidade visual que visa verificar os níveis de defeitos das peças;

g) Anotação dos dados na Folha de Verificação;

h) Entrega das Folhas de Verificação no final do turno ao analista de Qualidade.

Caso as dimensões estejam fora dos limites ou os níveis de defeitos estejam acima do normal, o inspetor de qualidade deve avisar o operador da moldureira para corrigir as dimensões e defeitos, e assinar na folha de verificação. Qualquer anormalidade deve ser escrita na folha de Verificação no campo de Observações para possível análise do analista de Qualidade. Dados como parada de máquina, repetição de algum defeito em excesso, anormalidades ou qualquer anotação que o faça necessário.

Quanto à qualidade visual as peças que estiverem conformes são devolvidas para serem embaladas. As peças que necessitem de algum reparo voltam para serem corrigidas com massa ou lixamento dependendo do defeito e as peças que não tiverem recuperação são separadas para mais tarde serem destopadas em comprimentos menores. Caso o pacote amostrado tenha uma porcentagem muito alta de defeitos, pois o aceitável é de 5\%, o pacote deve ser re-inspecionado, ou seja, os funcionários têm que inspecionar todo o pacote novamente, para que os defeitos não passem para frente, causando mais trabalho aos outros setores, o que ocasiona perda de tempo e aumento dos custos.

\section{Resultados e discussão}

\subsection{Levantamento dos níveis de defeitos - inspeção de qualidade visual}

Com o auxilio das ferramentas de qualidade, Diagrama de Pareto e Gráfico de Controle por Atributos (P - Fração Defeituosa) foram possível chegar aos seguintes resultados abaixo como mostra as Figuras 14 e 15. 


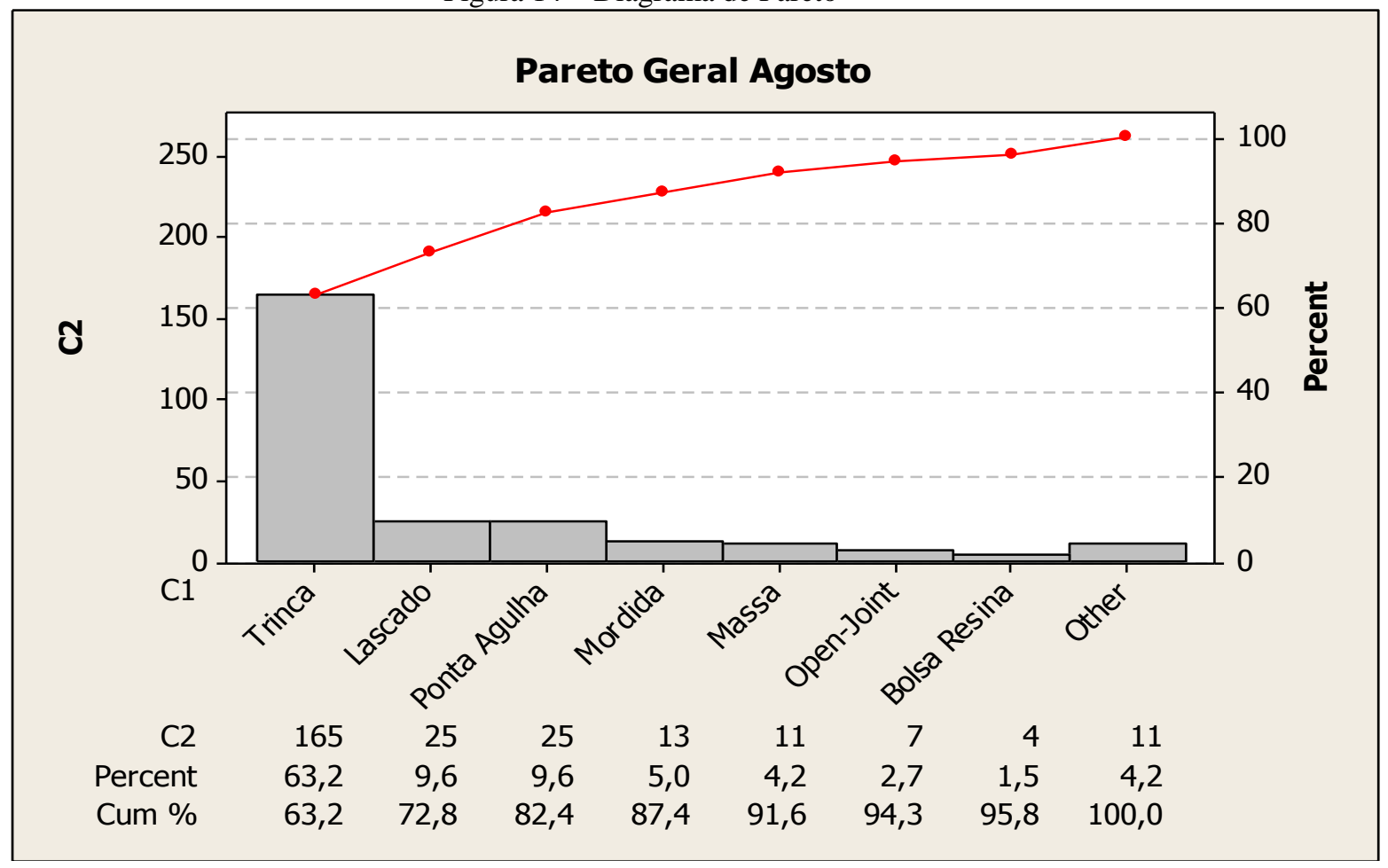

Como mostra o Diagrama de Pareto acima do mês analisado os 3 maiores defeitos que se apresentam neste mês foram trincas, lascados e pontas de agulha seguidos por mordida, massa, open joint e bolsa de resina respectivamente. Ou seja, os problemas devem ser resolvidos nesta ordem começando pela trinca até os menos relevantes.

Dentre os 13 tipos de defeitos possíveis nas molduras esses três são os mais presentes e devem ser tratados como prioridade, pois estes três defeitos trarão maiores benefícios caso sejam solucionados.

No Gráfico abaixo são avaliados as proporções de defeitos das molduras, como se percebe na Figura 15 , tem quatro pontos acima do LSC (Limite Superior de Controle), ponto 2, 10,11 e 13 demonstrando um descontrole do processo. 
Figura15 - Gráfico de fração defeituosa (p) com amostra de tamanho variavel

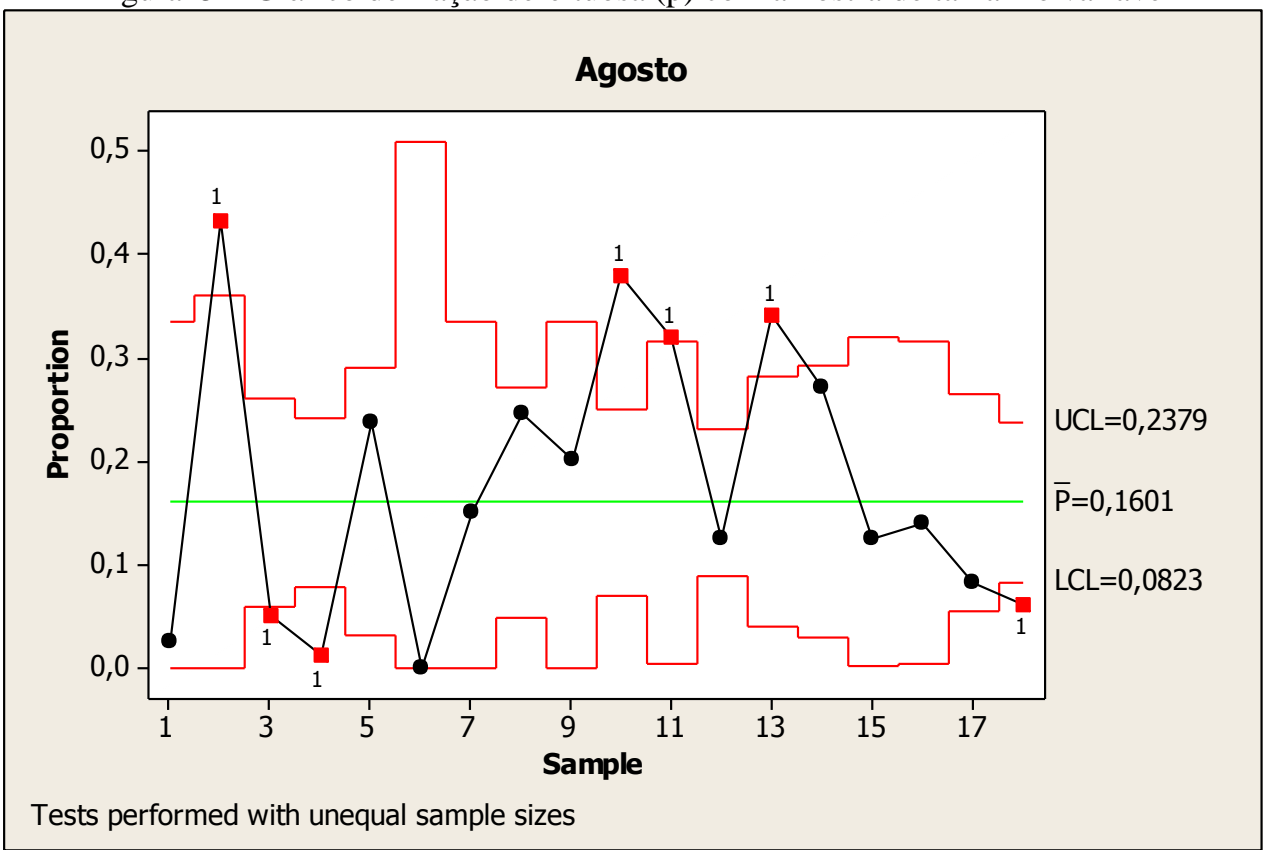

O Gráfico 15, Gráficos de Fração Defeituosa (p), foram utilizados em relação aos gráficos de número de Itens Defeituosos (np) pois apresentam tamanhos de amostra variáveis, iferentes dos gráficos (np) que têm amostra de tamanha constante.

\subsection{Levantamento dos níveis de dimensão - inspeção dimensional}

Com a ajuda do histograma pode-se verificar essas especificações do produto, assim pode-se saber se o processo está sob controle.

Abaixo na Tabela 1 estão elencados os modelos e suas diversas especificações.

Tabela 1 - Tabela com modelo e especificações do produto

\begin{tabular}{|c|c|c|c|c|}
\hline \multicolumn{2}{|c|}{ Produto } & \multicolumn{3}{|c|}{ Especificação } \\
\hline Modelo & $\mathrm{N}^{\mathrm{o}}$ Desenho & Espessura(Milímetros) & Largura(Milímetros) & Tolerância(Milímetros) \\
\hline EC445 Casing & 41 & 17,46 & 82,55 & $\pm 0,79$ \\
\hline EC356 Casing & $44 \mathrm{p}$ & 17,46 & 57,15 & $\pm 0,79$ \\
\hline
\end{tabular}

\subsection{Histograma para espessura}

Nesta parte serão avaliados os níveis de capacidade e estabilidade do processo. 
Figura 16 - Histograma avalia espessura do modelo EC356

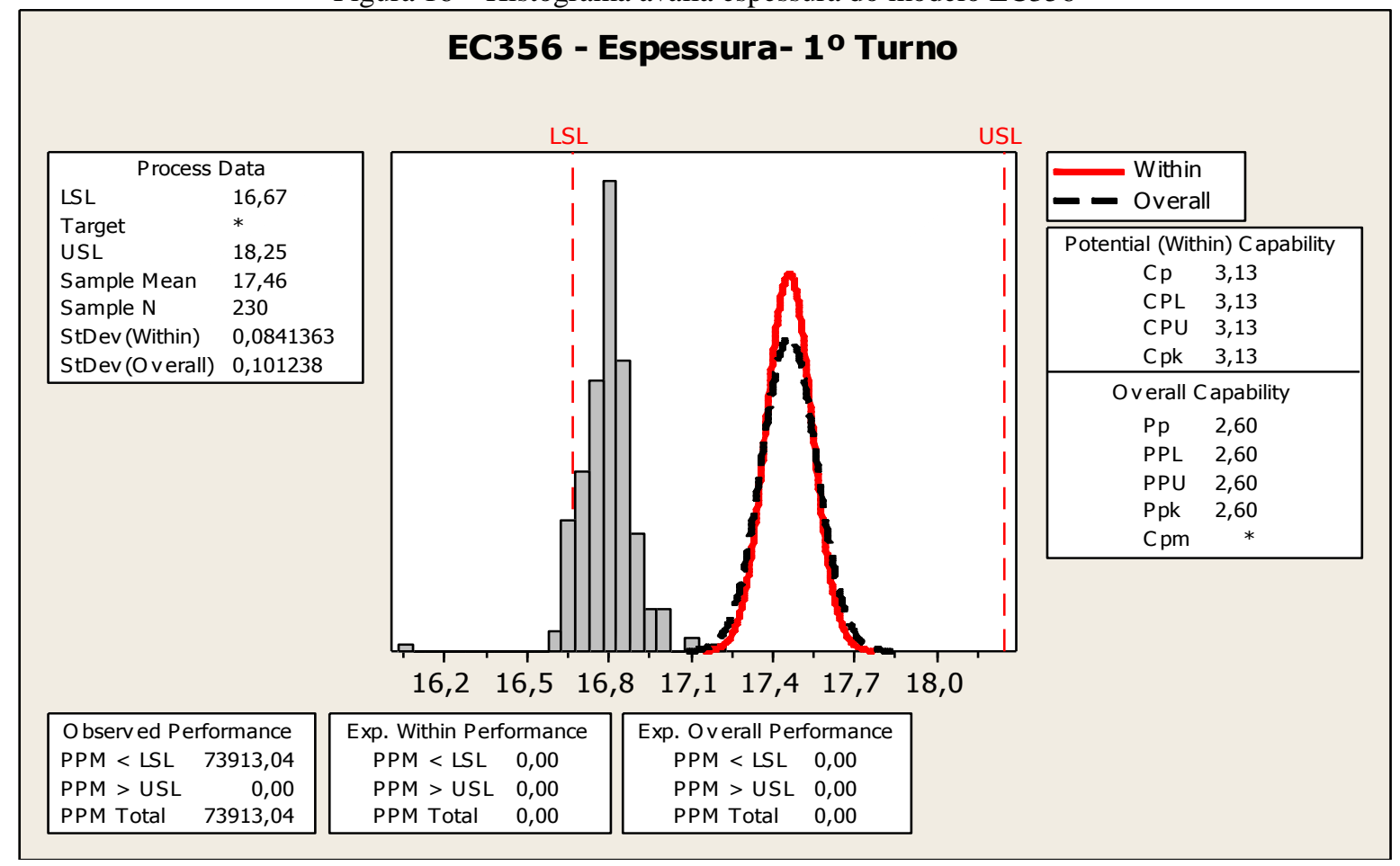

Na Figura 16 os dados estão deslocados para a esquerda e alguns estão fora do limite, causando perdas na produção devido às amostras estarem abaixo do limite, mesmo apresentando um cp alto de 3,13, este apresenta um descontrole não em variabilidade mas em limites inferiores, ocorrendo perdas de itens.

Figura 17 - Histograma avalia espessura do modelo EC356

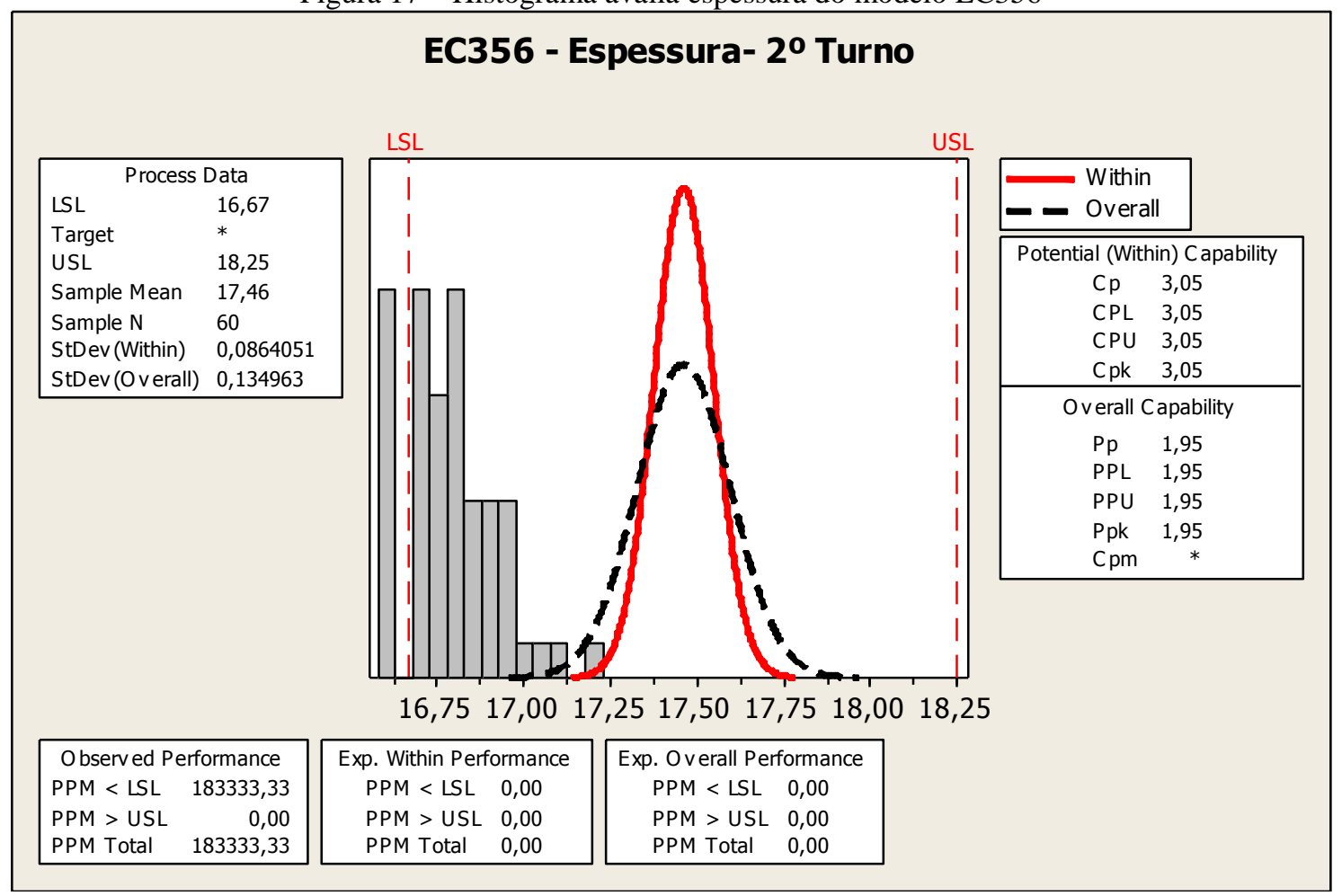


Na Figura 17, algumas amostras estão abaixo do limite e o ponto médio esta deslocado para a esquerda.

Neste o Cp mantém alto, mas a variabilidade reduz de 3,13 para 3,04 e vários pontos ocorrem abaixo do limite inferior LSL.

Figura 18 - Histograma avalia espessura do modelo EC445

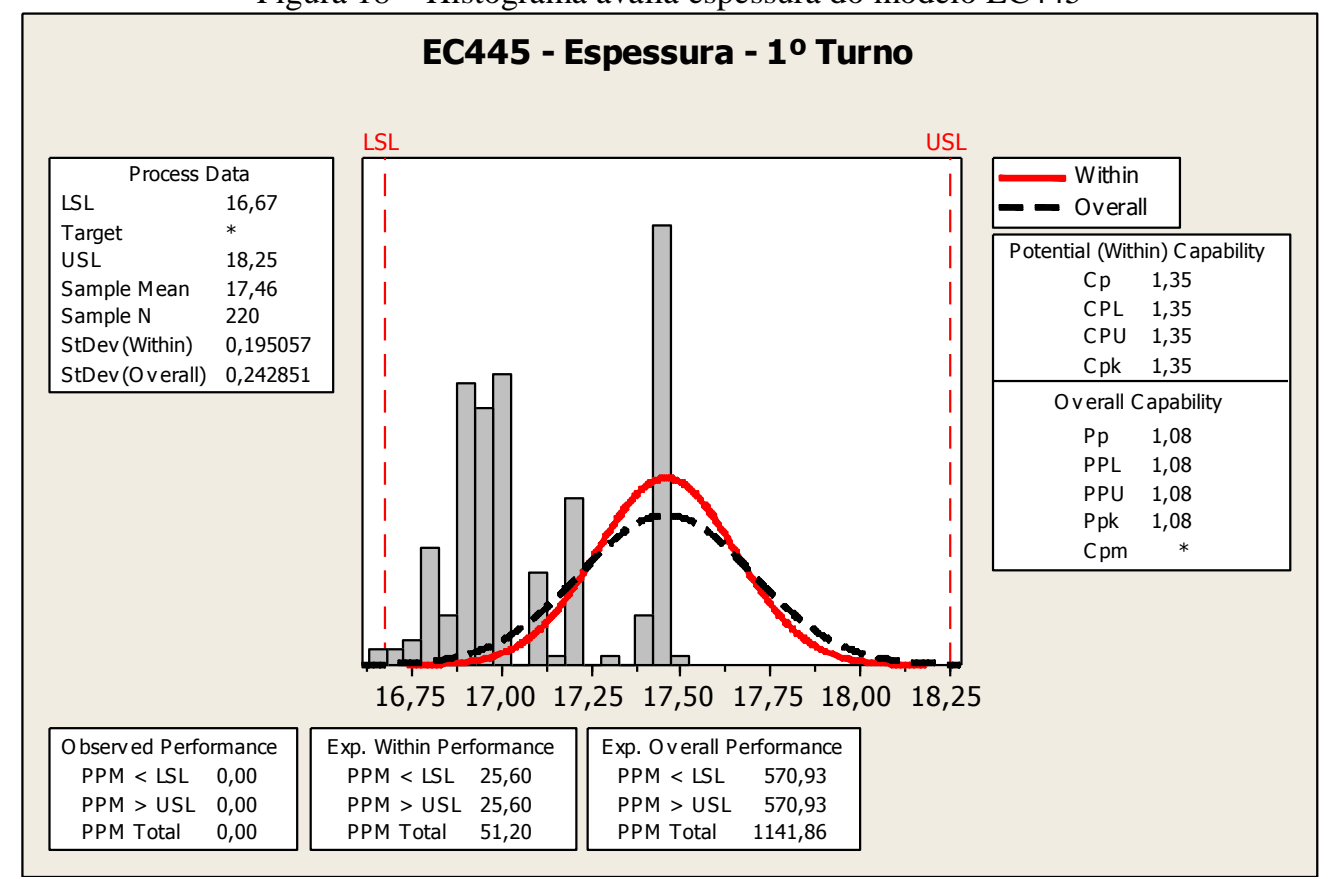

A Figura 18 mostra alguns pontos fora do limite e o ponto médio deslocado para a esquerda com grande variabilidade. Apesar de o $\mathrm{Cp}$ ser maior de 1,0, ocorrem itens-não conformes.

Figura 19 - Histograma avalia espessura do modelo EC445

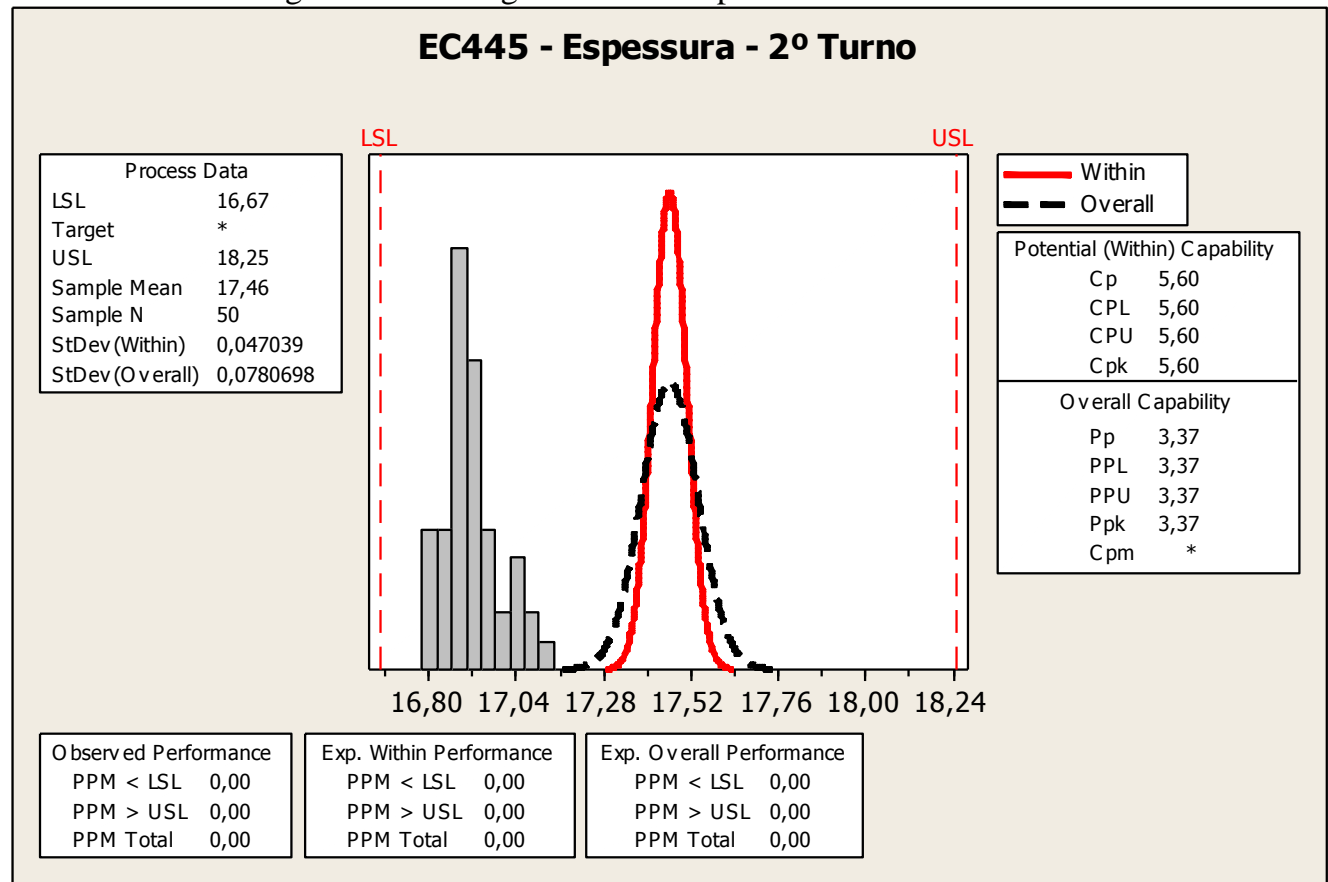


O histograma da Figura 19 mostra que os pontos estão dentro dos limites, mas estão deslocados para a esquerda. O Cp apresenta-se alto, mas apesar de estar dentro dos limites ocorre uma tendência a não respeitar os limites inferiores de especificação ( LSL).

\subsection{Análise dos resultados}

Após observação nos resultados anteriores foi discutido com a equipe e realizada o diagrama de causa e efeito.

a) Método: Não existe um procedimento adequado para cada operação, falta de padronização em pressões nas máquinas finger (que produzem Blancks) e níveis de cola, podendo causar aberturas de finger;

b) Máquina: Muitas máquinas são antigas e não recebem cuidados necessários para mantê-las em funcionamento com qualidade e o normalmente utiliza peças até o fim, ou seja, peças da máquina que já deveriam ser trocadas continuam em funcionamento até o fim;

c) Medida: possível falta de calibração adequada das máquinas ou dos equipamentos de medição;

d) Matéria-prima: madeira oriunda de reflorestamento sem planejamento, trazendo a fabrica madeiras de reações e madeiras juvenis para serem processadas;

e) Meio Ambiente: madeiras deixadas no campo por períodos maiores que 15 dias que podem causar defeitos como: azulados devido à presença de fungos, o que prejudica o produto final e também devido ao longo tempo de espera para processar o que diminui o teor de umidade da madeira e dificulta o beneficiamento na serraria para transformá-las em tábuas, dificuldade de uniformizar na estufa por estar com baixa umidade.

Para isso deve-se criar um plano de ação emergencial na empresa, para que possa resolver os problemas em questão.

De acordo com a empresa quando um lote tem $5 \%$ de defeitos deve ser rejeitado, mas na prática isto não funciona assim, muitas vezes o nível de defeito é maior e o lote e aceito, esse índice de 5\% não apresentava parâmetros, para isso deve-se utilizar a curva característica de operação, para descobrir a porcentagem máxima de unidades defeituosas.

Deve-se também classificar os defeitos de acordo com níveis, quais são mais críticos e os menos críticos, criando uma espécie de valor, de acordo com o nível e o número de defeitos faz-se uma equação, assim obtendo uma padronização dos defeitos, pois no momento não existe uma padronização dos defeitos.

\subsection{Plano de ação}

Para que possa melhorar o processo algumas etapas devem ser seguidas: 
a) Primeiramente é necessário mudar a política cultura da empresa, para conseguir implantar novas idéias;

b) Mostrar o verdadeiro significado de Qualidade, não de senso comum;

c) Treinamento adequado para todos da empresa (na função exercida), desde a alta gerência até a produção;

d) Treinamento de Gestão de Qualidade para engenheiros e inspetores e operadores, pois se sabe que um grande problema é o mau entendimento das ferramentas de qualidade, que muitas vezes ocorrem;

e) Criar procedimentos adequados para cada operação;

f) Utilizar o CEP em tempo real, ou seja, coletar os dados e no mesmo momento gerar os gráficos para evitar um aumento de produtos fora das especificações;

g) Disponibilidade dos dados imediata para os operadores e supervisores;

h) Criar equipes de qualidade para que possam solucionar problemas através de ferramentas como Brainstorming e ajudar outros colaboradores na questão de aprendizado sobre qualidade;

i) Empresas que já tiveram algum insucesso com alguma ferramenta de gestão de qualidade tendem a ter funcionários que se oponham as inovações propostas pela diretoria (INDEZEICHAK e LEITE, 2006).

\section{Conclusão}

A ferramenta CEP utilizada na empresa mostra-se ineficiente e necessita de melhorias na sua implantação e com isso controlar o processo trazendo melhorias para a empresa. A empresa necessita de uma mudança cultural, para que o CEP e outras ferramentas da qualidade sejam aceitas e utilizadas de maneira correta.

Apesar das análises dos resultados dos gráficos de controle terem mostrado que o processo é instável, os histogramas demonstraram que o processo é capaz, ou seja, o processo é capaz e instável, demonstrando que o processo é capaz de atender as especificações do produto, mas que em determinados momentos pode sair das especificações do produto.

O grande problema da instabilidade do processo são as causas especiais, que devem ser estudadas, para assim corrigi-las e futuramente criar planos de prevenção para que não ocorram novamente.

Através do diagrama de Pareto foi possível identificar os principais defeitos do processo, os quais são trinca ponta de agulha e lascado, onde devem ser resolvidos primeiramente.

Caso não ocorram mudanças de postura em relação à política de qualidade da empresa, os processos podem não atender mais as especificações do mercado levando assim a perdas de 
concorrência, pois as empresas cada dia mais procuram parceiros certificados pela ISO 9001:2008, onde o monitoramento de seus processos de produção atenda as especificações de seus clientes.

O CEP deve ser difundido para todos da empresa, principalmente aqueles que o controlam, tendo capacidade para atuar sobre os itens que o causam. Utilizar o CEP em tempo real para evitar que processos em descontrole, não causem grandes prejuízos devido à demora da descoberta.

$\mathrm{O}$ estudo de caso também avaliou as necessidades para que O CEP possa funcionar corretamente na empresa, necessitando de algumas mudanças para que assim, seja uma ferramenta adequada no controle de processo. O processo necessita de melhorias já que não atendem bem as especificações. Avaliando as necessidades que a empresa necessita para a melhoria da gestão da qualidade, bem como as dificuldades que apresentam durante a implantação do CEP.

\begin{abstract}
This study of Statistical Process Control - SPC, in a stage production of an industrial frame, aiming to use the tool of statistical process control (SPC) to assess the process capability. Where the process needs improvement as well not meet the specifications. Assessing the needs that the company needs to improve quality management, and the difficulties they present during the implementation of the CEP. The present study is to use the method of case study. The results are presented through study of the level of defects using Pareto diagrams and control chart by - (p) fraction defective, and checking the capacity and stability of the process using histograms. The process demonstrated the need for improvements in process and quality management. At the end of the work are presented suggestions for improving the quality system of the company.
\end{abstract}

Keywords: quality; statistical process control; lumber industrial.

\title{
Referências
}

ALENCAR, J. R. Uso de Controle Estatístico de Processo (CEP) para validação de processo de glibenclamida comprimidos. Revista Brasileira de Farmácia, v. 85, n. 3, p. 115-119 2004.

BARÇANTE, L. C. Qualidade Total, uma visão brasileira. Rio de Janeiro: Campus,1998.

CAMPOS,V. F. TQC - Controle da Qualidade Total no estilo japonês 8. ed. Rio de Janeiro:Bloch,2004.

CAMPOS, R. V. M.; ROCHA, R. P. O Controle Estatístico de Processos (CEP) para o monitoramento da qualidade do farelo lex no processo do óleo de soja na empresa CAC. In: IV Encontro de Produção Científica e Tecnológica, 4, 2009 , Campo Mourão - PR. Anais... Campo Mourão: NUPEM, 2009, 13p.

COSTA, A. F. B.; EPPRECHT, E. K.; CARPINETTI, L. C. R. Controle Estatístico de Qualidade. São Paulo: Atlas, 2004.

INDEZEICHAK, V.; LEITE, M. L. G. Análise do controle estatístico da produção para empresa de pequeno porte: um estudo de caso. In: XIII SIMPEP, 13, 2006, Bauru - SP. Anais... Bauru: SIMPEP, 2006, 12p.

INDEZEICHAK, V.; LEITE, M. L. G. Dificuldades para implantação do Controle Estatístico de Processo (CEP). In: XII SIMPEP, 12, 2005, Bauru - SP. Anais... Bauru: SIMPEP, 2005, 9p.

KUME, H. Métodos estatísticos para melhoria da qualidade. 7. ed. São Paulo: Gente, 1993.

MONTGOMERY, D. C. Introdução ao controle estatístico da qualidade. 2 ed., Rio de Janeiro: LTC. 
PALADINI, E. P. Gestão da Qualidade: Teoria e Prática. 2. ed. São Paulo: Atlas, 2004.

ROSÁRIO, M. B. Controle estatístico de processo: um estudo de caso em uma empresa de eletrodoméstico. 2004. 112f. Mestrado Profissionalizante em Engenharia - Universidade Federal do Rio Grande do Sul, Porto Alegre, 2004.

SIQUEIRA, L. G. P. Controle Estatístico do Processo. São Paulo: Pioneira, 1997.

SLACK, N., CHAMBER, S., HARDLANG, C., HARRISON, A., JOHNSTON, R. Administração da Produção. São Paulo. Editora: Atlas, 2009.

TOLEDO, J. C. Qualidade Industrial: concertos, sistemas e estratégias. São Paulo: Atlas,1987.

TORMINATO, S. M. Análise Da Utilização Da Ferramenta CEP: Um Estudo De Caso Na Manufatura de Autopeças. 2004. FOLHAS. Dissertação (mestrado profissional) Programa de Pós-Graduação em Engenharia Mecânica, Universidade Estadual de Campinas, 2004.

WERKEMA, M., C. As ferramentas da qualidade no gerenciamento de processos. Belo Horizonte: Fundação Christiano Otoni, 2006.

WICKRAMASINGHE, G.L.D.; WIJEBAHU ,W.M.S.K. Effects of Statistical Process Control (SPC) Practices on Quality Performance of the Apparel Firms. In: The Seventh International Research Conference on Management and Finance (IRCMF 2012). 2012.

\section{Dados dos autores}

Nome completo: Glaucia Aparecida Prates

Filiação institucional: UNESP- Universidade Estadual Paulista. " Julio de Mesquita Filho. Departamento: Faculdade de Engenharia

Função ou cargo ocupado: Professor assistente doutor

Endereço completo para correspondência (bairro, cidade, estado, país e CEP): Rua Geraldo Alckmin, 519. N. Sra. de Fatima. Itapeva. SP. CEP:18409010

Telefones para contato: 16 -996176212. ou 1535249100

e-mail: glaucia@itapeva.unesp.br

Nome completo: Reinaldo da Silveira Garcia

Filiação institucional: Universidade Estadual Paulista- UNESP

Departamento: Faculdade de Engenharia

Função ou cargo ocupado: Engenheiro Indsutrial Madeireiro

Endereço completo para correspondência (bairro, cidade, estado, país e CEP): Rua Geraldo Alckmin, 519. N. Sra. de Fatima. Itapeva. SP. CEp:18409010

Telefones para contato: (15) 3524-9100

e-mail: reinaldo.garcia.37@facebook.com

Submetido em: 02/10/2013

Aceito em: 13/10/2014 